\title{
KEPEMIMPINAN EFEKTIF KEPALA RUANGAN DENGAN BUDAYA KESELAMATAN PASIEN DI RSUD HAJI MAKASSAR
}

\author{
Adhyatma A ${ }^{1}$, Nurjannah ${ }^{2}$, Andi Alim ${ }^{3}$ \\ ${ }^{1,2,3}$ Fakultas Kesehatan Masyarakat, Universitas Pejuang Republik Indonesia, Jalan Gunung \\ Bawakaraeng Nomor 72 Kota Makassar \\ E-mail: adhyatma.askm89@gmail.com
}

\section{EFFECTIVE LEADERSHIP OF THE HEAD OF THE ROOM WITH PATIENT SAFETY CULTURE IN HAJI MAKASSAR HOSPITAL}

\begin{abstract}
Patient safety is a safe care system for patients in hospitals. Provision of safe care is a decrease in unsafe actions to patients and the provision of the best measures to obtain optimal patient health status in the health care system. This study aims to determine the relationship of the effective leadership of the head of the room with the application of patient safety culture in the inpatient ward of the Makassar Haji General Hospital in 2019. This study uses a non-experimental research type, with a quantitative approach, correlation analysis and cross-sectional design. The sample in this study used a sample with a saturated sampling technique in which the entire population was used as a research sample of 68 nurses. The results showed that the knowledge variable had a significant relationship with the culture of patient safety in Makassar Haji General Hospital $(p=0.020)$. The variable of self-awareness has a significant relationship with patient safety culture in Makassar Haji General Hospital $(p=0.005)$. The communication variable has a significant relationship with patient safety culture at the Makassar Haji General Hospital $(p=0.010)$. Energy use variable has a significant relationship with patient safety culture in Makassar Haji General Hospital ( $p=0.019)$. Therefore, it is hoped that the hospital will periodically include nurses in soft skill or hard skills improvement activities so that the increase in nurses' competencies and knowledge can continue to be improved.
\end{abstract}

Keywords: Effective leadership, patient safety culture, self-awareness, communication, energy use, patient safety

\begin{abstract}
Abstrak
Keselamatan pasien merupakan sistem pemberian asuhan yang aman bagi pasien di rumah sakit. Pemberian asuhan yang aman adalah penurunan tindakan yang tidak aman kepada pasien dan pemberian tindakan terbaik untuk mendapatkan derajat kesehatan pasien yang optimal dalam sistem pelayanan kesehatan. Penelitian ini bertujuan untuk mengetahui hubungan kepemimpinan efektif kepala ruangan dengan penerapan budaya keselamatan pasien di ruang rawat inap RSUD Haji Makassar Tahun 2019. Penelitian ini menggunakan jenis penelitian non-eksperimental, dengan pendekatan kuantitatif, analisis korelasi dan desain cross sectional. Sampel dalam penelitian menggunakan sampel dengan teknik sampling jenuh dimana seluruh jumlah populasi dijadikan sebagai sampel penelitian sebanyak 68 perawat. Hasil penelitian menunjukkan bahwa variabel pengetahuan memiliki hubungan yang signifikan dengan budaya keselamatan pasien di RSUD Haji Makassar $(\mathrm{p}=0,020)$. Variabel kesadaran diri memiliki hubungan yang signifikan dengan budaya keselamatan pasien di RSUD Haji Makassar $(\mathrm{p}=0,005)$. Variabel komunikasi memiliki hubungan yang signifikan dengan budaya keselamatan pasien di RSUD Haji Makassar $(\mathrm{p}=0,010)$. Variabel penggunaan energi memiliki
\end{abstract}


hubungan yang signifikan dengan budaya keselamatan pasien di RSUD Haji Makassar $(\mathrm{p}=0,019)$. Olehnya itu, diharapkan rumah sakit secara berkala mengikutsertakan perawat dalam kegiatan peningkatan soft skill ataupun hardskill sehingga peningkatan kompetensi serta pengetahuan perawat dapat terus ditingkatkan.

Kata kunci: Kepemimpinan Efektif, Budaya keselamatan pasien, Kesadaran Diri, Komunikasi, Penggunaan Energi, Keselamatan Pasien

\section{PENDAHULUAN \\ PENDAHULUAN}

Sistem pelayanan kesehatan yang perlu mendapatkan perhatian tentang keselamatan pasien bahkan sudah menjadi isu dunia saat ini. Keselamatan pasien merupakan hak bagi setiap pasien di dalam menerima pelayanan kesehatan karena salah satu prinsip dasar di dalam memberikan pelayanan kesehatan pada pasien. Kementrian Kesehatan Republik Indonesia (2015) menjadikan hak pasien sebagai standar pertama pada tujuh standar keselamatan pasien rumah sakit ${ }^{(1)}$. World Health Organization (WHO) Collaborating Center for Patient Safety Solutions bekerja sama dengan Joint Comission and Joint Comission International telah memasukkan masalah keselamatan pasien dengan menerbitkan enam program kegiatan keselamatan pasien pada 2005 dan sembilan panduan solusi keselamatan pasien di rumah sakit pada $2007^{(2)}$.

Sistem pemberian asuhan yang aman bagi pasien di rumah sakit merupakan keselamatan pasien (3). Pemberian asuhan yang aman menurut Linda McGillis Hall, Diane Doran, George H Pink (2004) adalah penurunan tindakan yang tidak aman kepada pasien dan pemberian tindakan terbaik untuk mendapatkan derajat kesehatan pasien yang optimal dalam sistem pelayanan kesehatan ${ }^{(4)}$. Keselamatan pasien adalah pasien bebas dari cedera yang tidak seharusnya terjadi atau bebas dari cedera yang potensial akan terjadi (penyakit, cedera fisik/sosial psikologis, cacat, kematian) terkait dengan pelayanan kesehatan $^{(5)}$.
Kondisi Potensial Cedera (KPC) merupakan kondisi yang sangat berpotensi untuk menimbulkan cedera, tetapi belum terjadi insiden. Kejadian Nyaris Cedera (KNC) merupakan terjadinya insiden yang belum sampai terpapar ke pasien. Kejadian Tidak Cedera (KTC) merupakan insiden yang sudah terpapar ke pasien, tetapi tidak timbul cedera. Kejadian Tidak Diharapkan (KTD) merupakan Insiden yang mengakibatkan cedera pada pasien. Suatu Kejadian Tidak Diharapkan (KTD) yang mengakibatkan kematian, cedera permanen, atau cedera berat yang temporer dan membutuhkan intervensi untuk mempetahankan kehidupan, baik fisik maupun psikis, yang tidak terkait dengan perjalanan penyakit atau keadaan pasien disebut sebagai Kejadian sentinel ${ }^{(6)}$.

Keselamatan (safety) telah menjadi isu global termasuk juga untuk rumah sakit. Menurut Thomas dan Brennan (2000) dalam Dwi Setiowati (2010) menyatakan bahwa sejak Institute of Medicine di Amerika Serikat menerbitkan laporan yang mengagetkan banyak pihak "to error is human", "Building a Safer Health System". Laporan itu mengemukakan penelitian di rumah sakit yang ada di Utah dan Colorado serta New York. Di Utah dan Colorado ditemukan KTD (Adverse Event) sebesar 2,9\% yang $6,6 \%$ diantaranya meninggal. Di New York KTD adalah sebesar 3,7\% dengan angka kematian 13,6\%. Angka kematian akibat KTD pada pasien rawat inap di seluruh Amerika yang berjumlah 33,6 juta per tahun berkisar 44.000-98.000 per tahun $^{(7)}$. Publikasi WHO tahun 2004, mengumpulkan angka-angka penelitian rumah sakit di berbagai negara, yaitu 
Amerika, Inggris, Denmark, dan Australia, ditemukan KTD dengan rentang 3,216,6\%. Dengan data-data tersebut, berbagai negara segera melakukan penelitian dan mengembangkan Sistem Keselamatan Pasien ${ }^{(8)}$.

Cedera yang terjadi pada pasien disebabkan kesalahan akibat melaksanakan suatu tindakan (Commission) atau tidak mengambil tindakan yang seharusnya diambil (omission). ${ }^{(9)}$ Webair et al., 2015 dalam Yeni Yarnita, Maswarni (2019) Institute of Medicine (IOM) pada tahun 2008 melaporkan angka Kejadian Tidak Diharapkan (KTD) pada rumah sakit di Amerika Serikat yaitu 1.5 juta pasien terluka pertahun dari kesalahan pengobatan, dan 7000 diantaranya dilaporkan meninggal. ${ }^{(10)}$

Menurut Agency for Health Care Research and Quality (AHRQ) pada 2008 yang di kutip oleh Nadzam, (2009) dalam Dwi Mardian Karyadi Putra (2014) melaporkan 2,5 juta pasien berisiko mengalami luka tekan per tahun di Amerika Serikat. Morse melaporkan 2,2-7 kejadian pasien jatuh/1000 tempat tidur per hari di ruang perawatan akut per tahun, 29$48 \%$ pasien mengalami luka, dan $7,5 \%$ dengan luka-luka serius. National Nosocomial Infections Surveillance System (NNISS) melaporkan kejadian infeksi nosokomial, ditemukan 5 infeksi setiap 1.000 pasien di ruang perawatan akut dan terdapat lebih dari 2 juta kasus per tahun, hal ini menimbulkan dua kali risiko kesakitan dan kematian. ${ }^{(11)}$

Berdasarkan laporan pada tahun 2010 oleh KKP-RS dalam Rosita Jayanti Bardan (2017) pada bulan Januari sampai dengan bulan April, Provinsi Jawa Barat menempati urutan pertama mengenai KTD sebesar 33,33\%, Banten dan Jawa Tengah $20 \%$, DKI Jakarta 16,67\%, Bali 6,67\%, Jawa Timur 3,33\%. Berdasarkan penyebab kejadian lebih dari 70\% di akibatkan oleh tiga hal yaitu masalah prosedur, dokumentasi, dan medikasi. Data-data di atas menunjukkan bahwa banyaknya masalah patient safety yang seharusnya dapat di cegah dengan penerapan standar International Patient Safety Goal dalam akreditasi JCI. $^{(12)}$

Kejadian KTD di Indonesia sebenarnya belum terlalu terwakilkan dari Data tentang KTD di atas. Data tentang KTD di Indonesia masih tergolong langka untuk di ketahui apalagi untuk kejadian nayaris cedera, kejadian malpraktek masih banyak terungkap di berbagai media informasi. Hal ini terjadi dikarenakan standar pelayanan kesehatan masih kurang optimal bilah di bandingkan dengan negara-negara maju lainnya seperti Amerika, Jepan dan Inggris. Bahkan di Indonesia sejak 2005 telah mencanankan "Gerakan Keselamatan Pasien Rumah Sakit" akan tetapi penerapan pencenaan tersebut masih belum komprenshif.

Menurut (Craven \& Hirnnie, 2000) dalam Hetty Ismainar, (2015) menyatakan bahwah ketidakpedulian akan keselamatan pasien menyebabkan kerugian bagi pasien dan pihak rumah sakit, yaitu biaya yang harus ditanggung pasien menjadi lebih besar, pasien semakin lama dirawat di rumah sakit, dan terjadinya resistensi obat. ${ }^{(13)}$ Menurut Chayono (2008) dalam Setya Budi Rahayu (2017) menyatakan akibat insiden pada pasien yaitu cidera, membahayakan jiwa, perpanjangan rawat, kematian. ${ }^{(14)}$ Nadzam, (2009) dalam Dwiana Dian (2016) menyatakan bahwah Kerugian bagi rumah sakit lainnya antara lain biaya yang hams dikeluarkan menjadi lebih besar yaitu pada upaya tindakan pencegahan terhadap kejadian, luka tekan, infeksi nosokomial, pasien jatuh dengan cidera, kesalahan obat yang mengakibatkan cidera. ${ }^{(3)}$ 
Peningkatan mutu pada keselamatan pasien perlu melibatkan dokter, perawat dan semua orang yang bekerja di sistem kesehatan wajib berkomitmen untuk merawat, membantu, menghibur dan merawat pasien dan memiliki keunggulan dalam penyediaan layanan kesehatan untuk semua orang yang membutuhkannya agar terwujud peningkatan keselamatan pasien di tatanan pelayanan kesehatan sebagai suatu bagian dalam sistem pelayanan kesehatan. ${ }^{(15)}$. Sama halnya dengan pernyataan Cahyono (2008) dalam IGA Ari Rasdiani, Ni Made Wedri dan IGA Mega (2014) yang menyebutkan bahwa kesalahan medis sangat jarang disebabkan oleh faktor kesalahan manusia secara tunggal namun lebih banyak disebabkan karena kesalahan sistem rumah sakit yang mengakibatkan rantai-rantai dalam sistem terputus. ${ }^{(16)}$

Pelayanan keperawatan berperan penting dalam penyelenggaraan upaya menjaga mutu pelayanan kesehatan di rumah sakit. ${ }^{(17)}$ Menurut Soeroso (2003) dalam Dwi Stiowati (2010) menyatakan bahwa jaminan mutu menjadi standar pertama dalam standar kinerja profesional perawat. ${ }^{(7)}$ Perawat yang memberi asuhan keperawatan selama 24 jam seharusnya memiliki peran penting dalam menjamin keselamatan pasien. ${ }^{(18)}$ Menurut Ramsey (2005) dalam Dwi Putra, Mardian Karyadi (2015) menyebutkan bahwa perawat memiliki peran yang dominan dalam mencegah terjadinya kesalahan pengobatan, diantaranya pelaporan kejadian, mendidik diri sendiri dan sesama perawat, memberikan rekomendasi tentang perubahan dalam prosedur dan kebijakan, dan keterlibatan dalam identifikasi masalah. ${ }^{(1)}$ Keselamatan pasien bagi perawat tidak hanya merupakan pedoman tentang apa yang seharusnya dilakukan, namun keselamatan pasien merupakan komitmen yang tertuang dalam kode etik perawat dalam memberikan pelayanan yang aman, sesuai kompetensi, dan berlandaskan kode etik bagi pasien. ${ }^{(19)}$

Terdapat faktor-faktor yang dapat berkontribusi terhadap terjadinya insiden keselamatan pasien seperti yang dikemukakan oleh Leape (1994); Dineen (2002); AHRQ (2003); Depkes (2008), Henrikson, et al (2008) yang dikutip oleh Dede Sri Mulyani (2013) meliputi faktor karakteristik individu, sifat dasar pekerjaan, lingkungan fisik, interaksi antara system dan manusia, lingkungan organisasi dan sosial, manajemen, dan lingkungan eksternal. (9) Peran kepemimpinan dalam meningkatkan keselamatan pasien juga telah menjadi standar kelima dalam standar keselamatan pasien rumah sakit di Indonesia. ${ }^{(1)}$

Kepemimpinan merupakan faktor penting dalam memberikan pengarahan kepada perawat untuk bekerja keras dengan penuh kemampuan untuk tujuan kelompok. kepemimpinan berpengaruh signifikan positif terhadap kinerja perawat, hal ini berarti dijelaskan bahwa faktor kepemimpinan berupa komunikasi antara pimpinan dan bawahan, tinggi rendahnya tingkat kepercayaan yang diberikan oleh pemimpin dapat mempengaruhi kinerja para perawat untuk mencapai tujuan organisasi. ${ }^{(20)}$ Menurut Walin (2005); Dian Pancaningrum, (2012) dalam Nonik Eka Martyastuti (2016) menyebutkan bahwa kepemimpinan dalam keperawatan meliputi manajer puncak (Direktur dan Wakil Direktur Keperawatan), manajer menengah (Kepala Bidang Keperawatan, Supervisor), dan manajer lini pertama (Kepala Ruang). ${ }^{(21)}$

Menurut Afrizal (2016)
pelaksanaan fungsi pengorganisasian
kepala ruang bertujuan untuk mencapai
tujuan yang sistematik, sehingga ada
pembagian tugas yang jelas, ada koordinasi


yang baik, terdapat pembagian tanggung jawab dan wewenang yang sesuai kemampuan serta keterampilan, serta terjalin hubungan yang baik antara perawat pelaksana dengan kepala ruang didalam melahirkan keselamatan pasien. ${ }^{(22)}$ Kepala ruang memiliki peran yang kritis dalam mendukung budaya keselamatan pasien dengan kepemimpinan efektif dalam menciptakan lingkungan yang positif bagi keselamatan pasien. Hal ini didukung oleh penelitian yang dilakukan Nurdiana, Tutik Sri Hariyati, Siti Anisah (2017) bahwa perawat manajer memiliki persepsi yang lebih positif terhadap budaya keselamatan pasien pada penerapan fungsi manajemen kepala ruangan dalam pengendalian mutu keperawatan pada rumah sakit yang ada di Jakarta. ${ }^{(23)}$

Tappen, Weiss, Whitehead, \& Fletcher, (2004) dalam Anugrah Warwati Anwar, Irwandy Kapalawi, M. Alimin Maidin (2014) yang menyatakan bahwah seorang pemimpin yang baik adalah seseorang yang pandai dalam mengambil keputusan yang tepat dan berorientasi pada tindakan. Pemimpin harus mengambil tindakan berdasarkan keenam komponen lainnya. Tindakan pemimpin efektif harus memperhatikan yaitu, pemimpin berorientasi pada kemampuan sebelum melakukan, tidak perlu menunggu orang lain dalam melakukan tindakan, melakukan perencanaan sebelum bertindak, bekerja sama dengan orang lain dalam bertindak, bertindak secara professional, mampu mengambil keputusan, mampu memberikan ide-ide, menggunakan teknik-teknik kepemimpinan dalam bertindak. ${ }^{(24)}$

Penelitian tentang kepemimpinan efektif yang dilakukan oleh Anugrah Warwati Anwar, Irwandy Kapalawi, M. Alimin Maidin (2014) yang menunjukkan bahwa kepemimpinan efektif kepala ruangan berhubungan dengan penerapan budaya keselamatan pasien $(\mathrm{p}=0,000$; $\mathrm{f}=0,651$ ) yang berarti hubungan kuat. Komponen kepemimpinan efektif yaitu pengetahuan, kesadaran diri, komunikasi, penggunaan energi, penentuan tujuan dan pengambilan tindakan terdapat hubungan dengan penerapan budaya keselamatan pasien di Instalasi Rawat Inap RSUD Kota Makassar ${ }^{(24)}$

Menurut Cahyono, (2008) dalam Freny R Mbaloto (2018) menyatakan bahwa keselamatan pasien merupakan transformasi budaya, seorang pemimpin dengan kepemimpinannya dapat melakukan perubahan budaya menuju keberhasilan program keselamatan pasien. Tantangan terbesar yang perlu dilakukan dalam menciptakan budaya keselamatan pasien yang terbuka adalah mendirikan dan mempertahankan budaya positif tentang keselamatan pasien pada organisasi pelayanan kesehatan. ${ }^{(25)}$ Peran perawat dalam isu keselamatan pasien adalah menciptakan budaya organisasi dengan komunikasi dan alur informasi yang jelas dan tepat ${ }^{(26)}$.

Di dalam sistem pelayanan, keselamatan pasien merupakan masalah yang sangat penting. Untuk mengidentifikasi insidensi keselamatan pasien telah dilakukan berbagai studi dan penelitian, pelaksanaan dan dampak keselamatan pasien yang kurang optimal, dan pelaksanaan program keselamatan pasien yang dilakukan oleh kepemimpinan perawat. Kepala ruangan memiliki peran yang kritis dalam mendukung budaya keselamatan pasien dengan kepemimpinan efektif telah menciptakan lingkungan yang positif bagi keselamatan pasien. Pertanyaan peneliti dalam penelitian ini adalah "Apakah ada hubungan antara kepemimpinan efektif kepala ruangan 
dengan penerapan budaya keselamatan pasien di RSUD Haji Makassar?”

\section{METODE PENELITIAN}

Penelitian ini menggunakan jenis penelitian non-eksperimental, dengan pendekatan kuantitatif, analisis korelasi dan desain cross sectional. Penelitian analitik korelasi digunakan karena peneliti ingin mendapatkan gambaran masingmasing variabel penelitian, dan menghubungkan dua variabel dan subvariabel masing-masing variabel dengan analisis korelasi serta dengan melakukan penelitian sesaat pada waktu tertentu saja. (27) Variabel bebas (independen) adalah persepsi perawat pelaksana terhadap kepemimpinan efektif kepala ruang, meliputi pengetahuan, kesadaran diri, komunikasi, penggunaan energi, penentuan tujuan, dan mengambil tindakan. Variabel tergantung (dependen) adalah penerapan budaya keselamatan pasien rumah sakit meliputi kerja sama, komunikasi terbuka, respon tidak menghukum terhadap kesalahan, dan pelaporan kejadian.

Variabel perancu (confounding) adalah karakteristik perawat di ruang rawat inap rumah sakit. Penelitian ini dilaksanakan di RSUD Haji Makassar yang diawali dengan penyebaran sejumlah kuisioner kepada seluruh perawat yang memenuhi kriteria responden. Penelitian ini akan dilaksanakan pada bulan Juli 2019. Populasi merupakan wilayah generalisasi yang terdiri atas objek/subjek yang mempunyai kuantitas dan karakteristik tertentu yang ditetapkan oleh peneliti untuk dipelajari dan kemudian ditarik kesimpulan. Populasi penelitian ini adalah seluruh perawat yang bekerja di ruang rawat inap RSUD Haji Makassar sebanyak 232 orang. Sedangkan, sampel merupakan sebagian dari populasi yang nilai/karakteristiknya dapat diukur dan nantinya dipakai untuk menduga karakteristik populasi ${ }^{(28)}$.

Kriteria inklusi dalam penelitian ini adalah bidan pelaksana yang bekerja di ruang rawat inap rumah sakit, bersedia menjadi responden penelitian, dapat membaca dan menulis dengan baik. Kriteria eksklusi dalam penelitian ini adalah perawat pelaksana dengan masa kerja kurang dari satu tahun dengan alasan perawat dengan masa kerja kurang satu tahun belum terpapar dan belum beradaptasi dengan lingkungan tempat perawat tersebut bekerja. Kriteria eksklusi yang lain adalah perawat yang sedang masa tugas/ijin belajar dan sedang dalam masa cuti (cuti hamil, cuti melahirkan, cuti menikah, cuti sakit). Dalam penelitian ini, peneliti mengambil sampel dengan teknik sampling jenuh dimana seluruh jumlah populasi yang tergolong ke dalam kriteria inklusi dijadikan sebagai sampel penelitian.

Penelitian ini didasarkan atas beberapa jenis data, yakni data primer dan data sekunder. Data primer adalah data yang diperoleh secara langsung dari responden dengan menggunakan panduan wawancara dan penyebaran kuesioner. Sedangkan data sekunder adalah data yang diperoleh dari rumah sakit, literatur, buletin, jurnal maupun kepustakaan lainnya yang relevan dengan penelitian ini. Peneliti mengunakan kuesioner sebagai alat pengumpul data. Kuesioner berisi daftar pernyataan yang sudah tersusun dengan baik dan responden hanya 
memberikan jawaban atau dengan memberikan tanda-tanda tertentu. (29) Kuesioner dalam penelitian ini meliputi: Kuesioner A berisi identitas perawat ruangan terdiri dari usia, jenis kelamin, masa kerja, tingkat pendidikan, dan pelatihan yang pernah diikuti; Kuesioner B berisi kepemimpinan efektif yang meliputi pengetahuan, kesadaran diri, komunikasi, dan penggunaan energy; dan Kuesioner C berisi penilaian kinerja perawat dalam penerapan keselamatan pasien. Untuk kepentingan analisis data digunakan program SPSS. Adapun langkah-langkah analisis data yang akan dilakukan adalah analisis univariat dengan cara data yang telah dikumpulkan sesuai instrumen pengumpulan data yang digunakan, diolah dan dianalisa dengan menggunakan metode statistik deskriptif, yakni menyajikan data dalam bentuk tabel distribusi frekuensi dan persentase dari setiap kejadian. Setelah diperoleh hasil dari pengolahan data yang dilakukan kemudian diinterpretasikan dan hasilnya disajikan secara naratif yakni memberikan penjelasan sesuai dengan kejadian atau fakta-fakta yang ditemukan di lapangan. Sedangkan, Analisis bivariat dilakukan terhadap dua variabel yang diduga berhubungan atau berkorelasi. Analisis ini dilakukan untuk mengetahui hubungan variabel dependen dan independen dalam bentuk tabung silang (Crosstab). Dengan menggunakan system komputerisasi program SPSS dengan uji statistik Chisquare.

\section{HASIL DAN PEMBAHASAN}

Hasil Penelitian

Karakteristik Responden

Tabel 1 Distribusi Frekuensi Responden Menurut Kelompok Umur, Jenis Kelamin, Tingkat Pendidikan, Masa Kerja, Status Kepegawaian dan Pelatihan di RSUD Haji Makassar Tahun 2019

\begin{tabular}{lcc}
\hline Variabel & n & Persentase \\
\hline Umur & & \\
$20-25$ & 21 & 30.9 \\
$26-30$ & 34 & 50.0 \\
$31-35$ & 9 & 13.2 \\
$36-40$ & 2 & 2.9 \\
$41-45$ & 2 & 2.9 \\
\hline Jenis Kelamin & & \\
Laki-laki & 25 & 36,8 \\
Perempuan & 43 & 63,2 \\
\hline Tingkat Pendidikan & & \\
SPK & 1 & 1,5 \\
D3 Keperawatan & 7 & 10,3 \\
S1 Keperawatan & 23 & 33,8 \\
NERS & 29 & 42,6 \\
S2 Keperawatan & 8 & 11,8 \\
\hline Masa Kerja & & \\
1-5 & 38 & 55,9 \\
11-15 & 23 & 33,8 \\
& 6 & 8,8
\end{tabular}




\begin{tabular}{lcc}
$16-20$ & 1 & 1,5 \\
\hline Status Kepegawaian & & \\
PNS & 42 & 61.8 \\
NON PNS & 26 & 38.2 \\
\hline Pelatihan & & \\
Pernah & 59 & 86,8 \\
Tidak Pernah & 9 & 13,2 \\
\hline
\end{tabular}

Sumber: Data primer, 2019

Tabel 2 menunjukkan bahwa dari 68 responden diperoleh data paling banyak berada pada rentang umur 26-30 tahun sebanyak $50 \%$ dan paling sedikit pada rentang umur 36-40 dan 41-45 tahun sebanyak 2,9\%. Sedangkan, untuk jenis kelamin menunjukkan bahwa dari 68 responden yang didata terdapat jenis kelamin laki-laki sebanyak $36,8 \%$ dan perempuan sebanyak 63,2\%.

Tabel 2 juga menunjukkan bahwa dari 68 responden yang didata terdapat tingkat pendidikan tertinggi yaitu NERS sebanyak $42,6 \%$ dan terendah yaitu SPK sebanyak $1,5 \%$. Sedangkan, untuk masa kerja menunjukkan bahwa dari 68 responden yang didata terdapat masa kerja tertinggi pada rentang 1-5 tahun sebanyak $55,9 \%$ dan terendah pada rentang 16-20 tahun sebanyak $1,5 \%$.

Tabel diatas juga menunjukkan bahwa dari 68 responden yang didata terdapat status kepegawaian PNS sebanyak 61,8\% dan Non PNS sebanyak 38,2\%. Sedangkan, untuk pelatihan menunjukkan bahwa dari 68 responden yang didata terdapat yang pernah mengikuti pelatihan sebanyak $86,8 \%$ dan tidak pernah sebanyak $13,2 \%$.

\section{Variabel Kepemimpinan Efektif}

Hasil perhitungan untuk keseluruhan jawaban responden mengenai variabel pengetahuan, kesadaran diri, Komunikasi,
Penggunaan energi dan keselamatan pasien ditampilkan pada tabel 2 .

Tabel 2 Distribusi Frekuensi Responden Menurut Variabel Pengetahuan, kesadaran diri, penggunaan energi dan keselamatan pasien di RSUD Haji Makassar Tahun 2019

\begin{tabular}{lcc}
\hline & n & Persentase \\
\hline Pengetahuan & & \\
Kurang & 34 & 50,0 \\
Baik & 34 & 50,0 \\
\hline Kesadaran Diri & & \\
Kurang & 9 & 13,2 \\
Baik & 59 & 86,8 \\
\hline Komunikasi & & \\
Kurang & 14 & 20.6 \\
Baik & 54 & 79,4 \\
\hline Penggunaan Energi & & \\
Kurang & 20 & 29,4 \\
Baik & 48 & 70,6 \\
\hline Keselamatan & & \\
Pasien & & \\
Kurang & 23 & 33,8 \\
Baik & 45 & 66,2 \\
\hline Sumber: Datapimer
\end{tabular}

Sumber: Data primer, 2019

Tabel 2 menunjukkan bahwa dari 68 responden yang didata terdapat variabel pengetahuan yang menjawab Baik sebanyak 50\% dan yang menjawab Kurang sebanyak $50 \%$. Sedangkan, untuk variabel kesadaran diri menunjukkan bahwa dari 68 responden yang didata terdapat variabel kesadaran diri yang menjawab Baik sebanyak $86,8 \%$ dan yang menjawab 
Kurang sebanyak 13,2\%. Tabel 2 juga menunjukkan bahwa dari 85 responden yang didata terdapat variabel Komunikasi yang menjawab Baik sebanyak 79,4\% dan yang menjawab Kurang sebanyak 20,6\%.

Tabel diatas juga menunjukkan bahwa dari 85 responden yang didata terdapat variabel penggunaan energi yang menjawab Baik sebanyak 70,6\% dan yang menjawab Kurang sebanyak 29,4\%. Sedangkan, untuk variabel budaya kesalamatan menunjukkan bahwa dari 68 responden yang didata terdapat variabel budaya keselamatan pasien yang menjawab Baik sebanyak 66,2\% dan yang menjawab Kurang sebanyak 33,8\%.

\section{Crosstab Variabel Independen dan Dependen}

Distribusi variabel pengetahuan, Kesadaran diri, Komunikasi, Penggunaan energi terhadap budaya keselamatan pasien dapat dilihat dalam tabel 3 .

Berdasarkan tabel 3 menjelaskan tentang hubungan antara pengetahuan dan budaya keselamatan pasien di RSUD Haji Makassar tahun 2019, dari 45 orang yang memiliki budaya keselamatan pasien yang baik terdapat 27 orang $(79,4 \%)$ responden dengan pengetahuan baik, sedangkan terdapat 18 orang $952,9 \%$ ) responden dengan pengetahuan kurang. Selanjutnya dari 23 orang yang memiliki budaya keselamatan pasien yang kurang, terdapat 7 orang $(20,6 \%)$ responden dengan pengetahuan baik, sedangkan terdapat 16 orang $(47,1 \%)$ responden dengan pengetahuan kurang. Berdasarkan uji statistik, di RSUD Haji Makassar didapatkan hasil chi square $\mathrm{X}^{2}=5,322$ dengan $p$ value $=0,020(\mathrm{p}<0,05)$. Dari hasil tersebut maka dapat disimpulkan bahwa ada hubungan yang bermakna/signifikan antara variabel pengetahuan budaya keselamatan pasien di RSUD Haji Makassar.

Pada tabel diatas juga menjelaskan tentang hubungan antara pengetahuan dan budaya keselamatan pasien di RSUD Haji Makassar tahun 2019, dari 45 orang yang memiliki budaya keselamatan pasien yang baik terdapat 40 orang $(74,1 \%)$ responden dengan pengetahuan baik, sedangkan terdapat 5 orang $(35,7 \%)$ responden dengan pengetahuan kurang. Selanjutnya dari 23 orang yang memiliki budaya keselamatan pasien yang kurang, terdapat 14 orang $(25,9 \%)$ responden dengan pengetahuan baik, sedangkan terdapat 9 orang $(64,3 \%)$ responden dengan pengetahuan kurang.

Tabel 1 Analisis Crosstab Antara Variabel Pengetahuan, Kesadaran diri, Komunikasi, Penggunaan energi Dengan Budaya Keselamatan Pasien Di RSUD Haji Makassar Tahun 2019

\begin{tabular}{|c|c|c|c|c|c|c|}
\hline \multirow{3}{*}{ Variabel } & \multicolumn{4}{|c|}{ Budaya Keselamatan Pasien } & \multirow{3}{*}{ Total } & \multirow{3}{*}{$\begin{array}{c}\text { Uji } \\
\text { Statistik }\end{array}$} \\
\hline & \multicolumn{2}{|c|}{ Kurang } & \multicolumn{2}{|c|}{ Baik } & & \\
\hline & $\mathbf{n}$ & $\%$ & $\mathbf{n}$ & $\%$ & & \\
\hline Pengetahuan & & & & & & $x^{2}=5,322$ \\
\hline Kurang & 16 & 47,1 & 18 & 52,9 & 39 & $\mathrm{p}=0,020$ \\
\hline Baik & 7 & 20,6 & 27 & 79,4 & 46 & $(p<005)$ \\
\hline Kesadaran Diri & & & & & & $x^{2}=8,953$ \\
\hline Kurang & 7 & 77,8 & 2 & 22,2 & 38 & $\mathrm{p}=0,005$ \\
\hline Baik & 16 & 27,1 & 43 & 72,9 & 47 & $(\mathrm{p}<005)$ \\
\hline Komunikasi & & & & & & $x^{2}=7,309$ \\
\hline
\end{tabular}


Jurnal Kesehatan Masyarakat, Vol. 5 No.2, Nov 2019 p-ISSN: 2442-8884 / e-ISSN: 2541-4542

DOI: http://dx.doi.org/10.35329/jkesmas.v5i2

\begin{tabular}{lcccccc} 
Kurang & 9 & 64,3 & 5 & 35,7 & 14 & $\mathrm{p}=0,010$ \\
Baik & 14 & 25,9 & 40 & 74,1 & 54 & $(\mathrm{p}<005)$ \\
\hline Penggunaan Energi & & & & & & $\mathrm{x}^{\mathbf{2}=5,677}$ \\
Kurang & 11 & 55 & 9 & 45 & 20 & $\mathrm{p}=0,019$ \\
Baik & 12 & 25 & 36 & 75 & 48 & $(\mathrm{p}<005)$ \\
\hline
\end{tabular}

Sumber: Data primer, 2019

Berdasarkan uji statistik, di RSUD Haji Makassar didapatkan hasil chi square $\mathrm{X}^{2}=7,309$ dengan $p$ value $=0,010$ $(\mathrm{p}<0,05)$. Dari hasil tersebut maka dapat disimpulkan bahwa ada hubungan yang bermakna/signifikan antara variabel komunikasi budaya keselamatan pasien di RSUD Haji Makassar.

Tabel 3 juga meperlihatkan hasil tentang hubungan antara pengetahuan dan budaya keselamatan pasien di RSUD Haji Makassar tahun 2019, dari 45 orang yang memiliki budaya keselamatan pasien yang baik terdapat 36 orang $(75 \%)$ responden dengan pengetahuan baik, sedangkan terdapat 9 orang $(45 \%)$ responden dengan pengetahuan kurang. Selanjutnya dari 23 orang yang memiliki budaya keselamatan pasien yang kurang, terdapat 12 orang (25\%) responden dengan pengetahuan baik, sedangkan terdapat 11 orang $(55 \%)$ responden dengan pengetahuan kurang. Berdasarkan uji statistik, di RSUD Haji Makassar didapatkan hasil chi square $\mathrm{X}^{2}=$ 5,677 dengan $p$ value $=0,019(\mathrm{p}<0,05)$. Dari hasil tersebut maka dapat disimpulkan bahwa ada hubungan yang bermakna/signifikan antara variabel penggunaan energi budaya keselamatan pasien di RSUD Haji Makassar.

\section{Pembahasan}

\section{Hubungan Pengetahuan Dengan Budaya Keselamatan Pasien}

Tabel 2 menunjukkan bahwa dari 68 responden yang didata terdapat variabel pengetahuan yang menjawab Baik sebanyak 50\% dan yang menjawab Kurang sebanyak 50\%. Sedangkan pada tabel 3 menunjukkan bahwa responden di RSUD Haji Makassar dengan variabel pengetahuan baik memiliki budaya keselamatan pasien baik sebanyak 79,4\% lebih besar dibandingkan dengan budaya keselamatan pasien kurang yaitu 20,6\%. Pada responden dengan variabel pengetahuan kurang, memiliki budaya keselamatan pasien baik sebanyak 52,9\%, lebih besar dibandingkan dengan budaya keselamatan pasien kurang yaitu 47,1\% .

Berdasarkan uji statistik, di RSUD Haji Makassar didapatkan hasil chi square $\mathrm{X}^{2}=5,322$ dengan $\mathrm{p}$ value $=0,020$ $(\mathrm{p}<0,05)$. Dari hasil tersebut maka dapat disimpulkan bahwa ada hubungan yang bermakna/signifikan antara variabel pengetahuan dengan budaya keselamatan pasien di RSUD Haji Makassar. Penelitian ini menemukan bahwa pengetahuan yang dimiliki oleh kepala ruangan tentang keilmuan dan keterampilan dalam keperawatan baik sehingga menerapakan budaya keselamatan pasien.

Hal ini didukung oleh penelitian yang dilakukan Dwi Setiowati, Allenidekania, Luknis Sabri (2014) menyatakan bahwa Pengetahuan merupakan komponen kepemimpinan efektif head nurse yang paling berhubungan dengan penerapan budaya keselamatan pasien oleh perawat pelaksana (30). Begitupula dengan hasil penelitian yang di lakukan oleh Anwar, et al (2016) yang menyatakan bahwa Secara umum, penelitian ini menunjukkan hasil bahwa terdapat hubungan yang signifikan antara pengetahuan kepala ruang dengan penerapan patient safety culture. ${ }^{(24)}$ 


\section{Hubungan Kesadaran Diri Dengan Budaya Keselamatan Pasien}

Tabel 2 menunjukkan bahwa dari 68 responden yang didata terdapat variabel kesadaran diri yang menjawab Baik sebanyak $86,8 \%$ dan yang menjawab Kurang sebanyak 13,2\%. Tabel 3 menunjukkan bahwa responden di RSUD Haji Makassar dengan variabel kesadaran diri baik memiliki budaya keselamatan pasien baik sebanyak 72,9\% lebih besar dibandingkan dengan budaya keselamatan pasien kurang yaitu $27,1 \%$. Pada responden dengan variabel kesadaran diri kurang, memiliki budaya keselamatan pasien baik sebanyak $22,2 \%$, lebih kecil dibandingkan dengan budaya keselamatan pasien kurang yaitu $77,8 \%$.

Berdasarkan uji statistik, di RSUD Haji Makassar didapatkan hasil chi square $\mathrm{X} 2=8,953$ dengan $\mathrm{p}$ value $=0,005$ $(\mathrm{p}<0,05)$. Dari hasil tersebut maka dapat disimpulkan bahwa ada hubungan yang bermakna/signifikan antara variabel kesadaran diri budaya keselamatan pasien di RSUD Haji Makassar. Penelitian ini menemukan bahwa kesadaran diri yang dimiliki oleh kepala ruangan tentang kemampuan berpikir, merasakan serta melakukan interaksi terhadap lingkungannya sehingga tercipta budaya keselamatan pasien.

Hasil penelitian ini sesuai dengan penelitian Anwar, et al (2017) yang menyatakan bahwa persepsi perawat terhadap fungsi pengarahan tidak sematamata karena pengarahan yang diberikan oleh kepala ruang, namun ada faktorfaktor lain yang memberikan pengaruh seperti kecakapan individu perawat itu sendiri, pengalaman kerja, dan kesadaran diri perawat terhadap peran dan tanggung jawabnya dalam upaya keselamatan pasien. Dewi (2016) juga menyatakan ada hubungan yang signifikan antara kepemimpinan dengan penerapan keselamatan pasien di ruang rawat inap RSUP Dr. M Djamil Padang. Kepemimpinan kepala ruangan yang baik akan meningkatkan penerapan keselamatan pasien oleh perawat pelaksana. (31).

\section{Hubungan Komunikasi Dengan Budaya Keselamatan Pasien}

Tabel 2 menunjukkan bahwa dari 85 responden yang didata terdapat variabel Komunikasi yang menjawab Baik sebanyak $79,4 \%$ dan yang menjawab Kurang sebanyak 20,6\%. Tabel 3 menunjukkan bahwa responden di RSUD Haji Makassar dengan variabel komunikasi baik memiliki budaya keselamatan pasien baik sebanyak $74,1 \%$ lebih besar dibandingkan dengan budaya keselamatan pasien kurang yaitu 25,9\%. Pada responden dengan variabel komunikasi kurang, memiliki budaya keselamatan pasien baik sebanyak $35,7 \%$, lebih kecil dibandingkan dengan budaya keselamatan pasien kurang yaitu 64,3\%.

Berdasarkan uji statistik, di RSUD Haji Makassar didapatkan hasil chi square $\mathrm{X}^{2}=7,309$ dengan $\mathrm{p}$ value $=0,010$ $(\mathrm{p}<0,05)$. Dari hasil tersebut maka dapat disimpulkan bahwa ada hubungan yang bermakna/signifikan antara variabel komunikasi budaya keselamatan pasien di RSUD Haji Makassar. Penelitian ini menemukan bahwa komunikasi yang dimiliki oleh kepala ruangan baik dalam kemampuan berkomunikasi secara verbal, tertulis, maupun secara lisan di dalam menciptakan budaya keselamatan pasien.

Hasil penelitian ini tidaka sejalan dengan penelitian yang dilakukan oleh Wardhani (2013) juga menegaskan bahwa hasil uji hubungan antara komunikasi dengan penerapan budaya keselamatan pasien menunjukkan bahwa tidak terdapat hubungan antara komunikasi yang dimiliki oleh kepala ruangan dengan penerapan budaya keselamatan pasien $(\mathrm{p}=0,532$, $\mathrm{p}>0,05)$ (32). Sedangkan penelitian yang di lakukan oleh Anwar, et al (2017) sejalan dengan penelitian ini yang menunjukan hasil uji hubungan antara komunikasi dengan penerapan budaya keselamatan pasien menunjukkan bahwa terdapat 
hubungan antara komunikasi yang dimiliki kepala ruanagan dengan penerapan budaya keselamatan pasien. ${ }^{(24)}$

\section{Hubungan Penggunaan Energi Dengan Budaya Keselamatan Pasien}

Tabel 2 menunjukkan bahwa dari 85 responden yang didata terdapat variabel penggunaan energi yang menjawab Baik sebanyak $70,6 \%$ dan yang menjawab Kurang sebanyak 29,4\%. Tabel 3 menunjukkan bahwa responden di RSUD Haji Makassar dengan variabel penggunaan energi baik memiliki budaya keselamatan pasien baik sebanyak $75 \%$ lebih besar dibandingkan dengan budaya keselamatan pasien kurang yaitu 25\%. Pada responden dengan variabel penggunaan energi kurang, memiliki budaya keselamatan pasien baik sebanyak $45 \%$, lebih kecil dibandingkan dengan budaya keselamatan pasien kurang yaitu $55 \%$.

Penelitian ini seiring dan sejalan dengan penelitian yang dilakukan oleh A. Era Rizki Pratiwi, Rini Anggraeni, M. Alimin Maidin (2014) yang menemukan bahwa Penggunaan energi kepala ruang 7 responden $(87,5 \%)$ tergolong baik dengan nilai diatas mean 11,62 , begitupun dengan penggunaan energi menurut perawat 80 responden $(80 \%)$ berada diatas nilai mean 11,95 yang di laksanakan di Instalasi Rawat Inap RSUD Kota Makassar. ${ }^{(33)}$

Berdasarkan uji statistik, di RSUD Haji Makassar didapatkan hasil chi square $\mathrm{X}^{2}=5,677$ dengan $\mathrm{p}$ value $=0,019$ $(\mathrm{p}<0,05)$. Dari hasil tersebut maka dapat disimpulkan bahwa ada hubungan yang bermakna/signifikan antara variabel penggunaan energi budaya keselamatan pasien di RSUD Haji Makassar. Penelitian ini menemukan bahwa penggunaan energi yang dimiliki oleh kepala ruangan baik dalam kemampuan menggunakan energi yang tinggi akan berdampak secara langsung kepada bawahannya. Energi tidak hanya pada penggunaan kekuatan fisik akan tetapi juga pada pengaturan perasaan dalam menciptakan budaya keselamatan pasien.

Hasil penelitian ini sesuai dengan penelitian Anwar, et al (2014) yang menyatakan bahwa terdapat ada hubungan antarapenggunaan energi dengan penerapan budaya keselamatan pasien $(\mathrm{p}=0,000 ; \mathrm{f}=529) \quad$ (24). Demikian pula dengan hasil penelitian yang dilakukan oleh Dwi Setiowati, Allenidekania, Luknis Sabri (2014) yang menyatakan bahwa penggunaan energi merupakan komponen kepemimpinan efektif head nurse yang paling tinggi. Penggunaan energi diterapkan baik oleh head nurse dengan rata-rata skor penilaian 15,9 (skor penilaianantara 15-20) yang di laksanakan di di RSUPN Dr. Cipto Mangunkusumo Jakarta. (30)

\section{KESIMPULAN}

Berdasarkan hasil penelitian tentang Hubungan Kepemimpinan Efektif Kepala Ruangan Dengan Budaya Keselamatan Pasien Di Ruang Rawat Inap RSUD Haji Makassar Makassar tahun 2019, maka dapat diambil kesimpulan ada hubungan yang signifikan antara variabel pengetahuan, kesadaran diri, komunikasi dan penggunaan energi dengan budaya keselamatan pasien di RSUD Haji Makassar Makassar. Berdasarkan hasil penelitian dan pembahasan serta kesimpulan di atas, maka peneliti memiliki saran kepada pihak rumah sakit dapat meningkatkan kapasitas pengetahuan perawatnya dengan lebih sering mengikuti pelatihan sesuai bidangnya; kepala ruangan lebih aktif dalam memberi motivasi kepada perawatnya sehingga kesadaran diri mengenai pekerjaan dapat terus ditingkatkan; meningkatkan komunikasi yang baik terhadap perawatnya sehingga tidak terjadi miss komunikasi yang dapat berakibat pada terganggunya pelayanan kepada pasien; serta selalu mengingatkan kepada perawatnya agar selalu bekerja seoptimal mungkin sehingga pelayanan 
dapat berlangsung dengan baik dan pasien merasa mendapat pelayanan terbaik.

\section{DAFTAR PUSTAKA}

1. KemKes R I. Pedoman Nasional Keselamatan Pasien Rumah Sakit. Jakarta; 2015.

2. WHO. WHO Collaborating Center for Patient Safety's Nine Life-Saving Patient Safety Solutions. Jt Comm J Qual Patient Saf. 2007;33(7):427.

3. Dian D. Hubungan Faktor Individu, Organisasi dan Psikologis Perawat dengan Penerapan Patient Safety di Ruang Rawat Inap RSUD Solok. Universitas Andalas; 2016.

4. Hall LM, Doran D, Pink GH. Nurse Staffing Models, Nursing Hours, and Patient Safety Outcomes. JONA J Nurs Adm. 2004;34(1):41-5.

5. Pagala I, Shaluhiyah Z, Widjasena B. Perilaku Kepatuhan Perawat Melaksanakan SOP Terhadap Kejadian Keselamatan Pasien di Rumah Sakit X Kendari. J Promosi Kesehat Indones. 2017;12(1):138-49.

6. Kemenkes RI. Peraturan Menteri Kesehatan Republik Indonesia Nomor 11 Tahun 2017 tentang Keselamatan Pasien. Jakarta Kementeri Kesehat Republik Indones. 2017;

7. Setiowati D. Hubungan Kepemimpinan Efektif Head Nurse dengan Penerapan Budaya Keselamatan Pasien oleh Perawat Pelaksana di RSUPN Dr. Cipto Mangkusumo Jakarta. Vol. 7, Cipto Mangunkusumo Jakarta [Tesis]. Depok: Universitas Indonesia. 2010.

8. DepKes R I. Panduan Nasional Keselamatan Pasien Rumah Sakit (Patient Safety). Departemen Kesehatan RI 2008.

9. Mulyana DS. Analisis Penyebab Insiden Keselamatan Pasien oleh
Perawat di Unit Rawat Inap Rumah Sakit X Jakarta. Universitas Indonesia. 2013.

10. Yarnita Y, Maswarni. Budaya Keselamatan Pasien pada Perawat di Instalasi Perawatan Intensive RSUD Arifin Achmad Provinsi Riau. J Keperawatan Prior. 2019;2(2):109-19.

11. Putra DMK. Hubungan Antara Beban Kerja Perawat dengan Implementasi Patient Safety di Ruang Anggrek dan Ruang Bougenville RSUD Ngudi Waluyo Wlingi Blitar. University of Muhammadiyah Malang; 2015.

12. Bardan RJ. Analisis Penerapan Keselamatan Pasien di Rumah Sakit Umum Daerah Inche Abdoel Moeis Tahun 2017. Universitas Hasanuddin; 2017.

13. Ismainar H. Keselamatan Pasien di Rumah Sakit. Yogyakarta: Deepublish Publisher. 2015.

14. Rahayu SB. Pengaruh Dimensi Staffing terhadap Insiden Keselamatan Pasien Berdasarkan Agency for Healthcare Research and Quality (AHRQ) di RSU Haji Surabaya. J Adm Kesehat Indones (JAKI)| Indones J Heal Adm. 2017;5(1):41-51.

15. Tutiany, Lindawati, Krisanti P. Bahan Ajar Keperawatan: Manajemen Keselamatan Pasien. Kementerian Kesehatan Republik Indonesia. Pusat Pendidikan Sumber Daya Manusia Kesehatan, Badan Pengembangan dan Pemberdayaan Sumber Daya Manusia Kesehatan, Kementrian Kesehatan Republik Indonesia; 2017. 297 p.

16. Rasdiani IA, Wedri NM, Mega I. Hubungan Penerapan Budaya Keselamatan Pasien dengan Supervisi Pelayanan Keperawatan oleh Perawat Pelaksana. Denpasar: Politeknik Kesehatan Denpasar; 2014.

17. Hartanto YD, Warsito BE. Kepemimpinan Kepala Ruang dalam 
Penerapan Budaya Keselamatan Pasien di Rumah Sakit: Literature Review. 2017;

18. Sitanggang R. Peran Perawat Menerapkan Prinsip Pasien Safety di RS. 2019;

19. Syam NS. Implementasi Budaya Keselamatan Pasien Oleh Perawat di Rumah Sakit Ibnu Sina Makassar. Fak Kesehat Masy. 2017;11(2):174-80.

20. Rahayu VT, Ariyani V, Kurniawan S. Pengaruh Kepemimpinan, Lingkungan Kerja Fisik, dan Kompensasi terhadap Kinerja Karyawan di PT. PLN Cabang Madiun. JRMA| J Ris Manaj dan Akunt. 2013;1(1):89-95.

21. Martyastuti NE, Dharmana E, Hidayati W. Hubungan Antara Faktor Individu dan Persepsi Organisasi dengan Kinerja Perawat Pelaksana Dalam Penerapan Keselamatan Pasien di Ruang Rawat Inap RSUD Bendan Kota Pekalongan. Diponegoro; 2016.

22. Afrizal, Pratiwi A, Yulian V. Analisis Fungsi Kepala Ruang Menurut Perspektif Staf Keperawatan Di RSJD Surakarta. Universitas Muhammadiyah Surakarta; 2016.

23. Nurdiana, Hariyati TS, Anisah S. Penerapan Fungsi Manajemen Kepala Ruangan dalam Pengendalian Mutu Keperawatan. J Persat Perawat Nas Indones. 2018;2(3):160-76.

24. Anwar AW, Kapalawi I, Maidin MA. Hubungan Kepemimpinan Efektif Kepala Ruangan dengan Penerapan Budaya Keselamatan Pasien di Instalasi Rawat Inap RSUD Kota Makassar. Universitas Hasanuddin; 2014.

25. Mbaloto FR. Strategic Leadership Kepala Ruangan dalam Penerapan Budaya Keselamatan Pasien oleh Perawat Pelaksana Di RSUD Undata
Palu. J Ilm Kesehat. 2018;9(1):10-6.

26. Handayani F. Peran Perawat dalam Melakukan Pengelolaan Keselamatan Pasien. 2019;

27. Sastroasmoro S, Ismael S. Dasar-dasar Metodologi Penelitian Klinis. Vol. 372, Jakarta: Sagung Seto. 2011.

28. Luknis S, Hastono SP. Statistik Kesehatan. Edisi Revisi. Jakarta: Rajagrafindo. 2008.

29. Notoatmodjo S. Metodologi Penelitian Kesehatan. Edisi Revi. Rineka Cipta. Jakarta, Indonesia; 2010.

30. Setiowati D, Allenidekania, Sabri L. Effective Leadership of Head Nurse Increase the Implementation ofd Patient Safety Culture by Nurse Practitioners of Dr. Cipto Mangunkusumo National Hospital, Jakarta. Makara J Heal Res. 2014;15(2):55-60.

31. Dewi S. Analisis Faktor-Faktor yang Berhubungan dengan Penerapan Keselamatan Pasien di Instalasi Rawat Inap RSUP. Dr. M. Djamil Padang Tahun 2016. Universitas Andalas; 2016.

32. Wardhani NB, Noor NB, Pasinringi SA. Hubungan Kepemimpinan Efektif Kepala Ruangan Dengan Penerapan Budaya Keselamatan Pasien Di Instalasi Rawat Inap RS UNHAS Tahun 2013. Hasil Penelitian, Bagian Manajemen Rumah Sakit, Fakultas Kesehatan ...; 2013.

33. Pratiwi AER, Anggraeni R, Maidin MA. Gambaran Kepemimpinan Efektif Kepala Ruangan Instalasi Rawat Inap dalam Penerapan Budaya Keselamatan Pasien di RSUD Haji. Bagian Manaj Rumah Sakit, Fak Kesehat Masyarakat, Univ Hasanuddin. 2014; 